\title{
STEM from the perspectives of engineering design and suggested tools and learning design
}

\author{
Yu-Liang Ting ${ }^{\mathrm{al}}$ \\ ${ }^{a}$ National Taiwan Normal University, Taipei, Taiwan
}

\begin{abstract}
STEM is an educational concept about which little consensus has been reached as to what it is, and how it can be taught in schools. This study provides a snap shot of prominent contemporary research results contributing to better understanding of STEM and its implementation in education. In addition, this study tries to tackle an issue that school science has traditionally been built around well defined problems for learning purpose. As most real-world problems are ill-defined, this study proposes to implement the notion of STEM to help students acquire real-world problem-solving skills by engaging them in an engineering design process, in which students use the technology tools of graphic-based programming. The proposed learning practice is experiential task-based learning, in which students are forced to apply and acquire related science and mathematics knowledge during their engineering design process. It is hoped that related rationales and discussions will stimulates researchers and educators to adopt or tailor their own learning designs for the current generation of youngsters and promote the quality of teaching and learning in STEM.
\end{abstract}

Keywords: Engineering design; Engineering design process; Experiential learning; Graphic-based programming tool

\section{Introduction}

STEM is an educational concept about which little consensus has been reached as to what it is, and how it can be taught in schools. Opinions vary as to whether it needs to be taught as a discrete subject or should be an approach to teaching component subjects, what progression should be followed in STEM education, and how STEM learning can be assessed (Pitt, 2009; Williams, 2011). Regarding each component in STEM, the S (Science), $\mathrm{T}$ (technology), and M (Mathematics) all have well-defined subject content and related courses in K-12 education. However, most school teachers are alien to the E, engineering. Katehi, Pearson, and Feder (2009) recommend that, in addition to developmentally appropriate knowledge and skills for mathematics, science, and technology, K-12 education should also focus on engineering design. Engineering addressed here concerns the type that utilizes knowledge in science and mathematics as well as the use of technological tools. Engineering or engineering design is about the design and creation of man-made products and a process for solving problems (Katehi, Pearson, \& Feder, 2009). This design process or problem solving involves a trade-off, and takes into consideration what engineers call constraints. One constraint is the laws of nature, or science. Other constraints include such things as time, economy, politics, social concerns, available materials, environmental regulations, manufacturability, and repairability. Awareness of these constraints result from knowledge of science.

\footnotetext{
${ }^{1}$ National Taiwan Normal University, Taipei, Taiwan. E-mail: yting@ntnu.edu.tw

Ting, Y.-L (2016). STEM from the perspectives of engineering design and suggested tools and learning design. Journal of Research in STEM Education, 2(1), 59-71
} 
In fact, engineering design is different from science inquiry. Science inquiry, as defined by the National Science Education Standards (NSES p. 23), includes the activities through which students develop knowledge and understanding of scientific ideas, as well as an understanding of how scientists study the natural world and propose explanations based on the evidence derived from their work. Being used as a way of understanding science content, science inquiry helps students learn how to ask questions and use evidence to answer them. In the process of scientific inquiry learning, students learn to conduct an investigation and collect evidence from a variety of sources, develop an explanation from the data, and communicate and defend their conclusions.

School science has traditionally been built around well defined problems. Much of the curricula and teaching practices used in schools have been criticized because their academicism does not give students experience associated with real-world problems in situations where decisions are not clear cut (Fortus et al., 2004). Several researchers and organizations have recommended to restructure school science around real-world issues to help students develop the knowledge and skills necessary in a science and technology rich world (Blumenfeld et al., 1991; Fortus et al., 2004). It therefore has been asserted that engineering design process is a needed training in school because most real-world problems are ill-defined, lack required information, and do not have a known, correct nor best solution (Fortus et al., 2004). In the learning of engineering design, students are required to use and integrate their knowledge of both science and mathematics to develop a technological solution to a problem. This is not meant to claim a priority of engineering design over scientific inquiry. Both science and engineering are equally important. Scientists discover new knowledge by peering into the unknown, and engineers need to base on these discoveries to create functional produces (Carlson \& Sullivan, 2004). Scientific inquiry is used to generate data for informing engineering design decisions. In education, engineering design can be used to provide contextualized opportunities for science learning (Katehi, Pearson, \& Feder, 2009). Scientific investigation and engineering design can mutually reinforce each other (Katehi, Pearson, \& Feder, 2009).

The engineering design manifests the science to be learned and the science that is learned directly impacts the modifications made to the design (Apedoe et al., 2008). The engineering design process does not only focus on having students apply the scientific knowledge that they have learned, but also support them to acquire and develop scientific knowledge in the context of designing artifacts (Fortus et al., 2005). That is, students learn the science concepts while they are engaged in design, rather than learning all the relevant concepts and then applying them to a design challenge. This elaboration not only reveals the relationship between scientific inquiry and engineering design, but also stands against the misconception of replacing scientific inquiry with engineering design, a mistake made by many school teachers in their early stage of implementing STEM.

Moreover, although the demand for engineers is increasing, the number of students pursuing careers in engineering is not (Hirsch et al., 2005). Apedoe et al. (2008) suggest that exposure to engineering design in the context of high school science is an effective way to encourage students to consider engineering as an important career option. Hirsch et al. (2005) established a program to provide school teachers with pre-engineering curriculum to better prepare students to enter engineering degree programs. The curriculum focused on pre-engineering skills and teachers learn to use instructional strategies that support students construct the connections between science, mathematics and engineering. Carlson and Sullivan (2004) also created an integrated learning program, in which students were introduced to the world of engineering and the iterative design process, including the use of technological tools and software. With the spirit of discovery learning spanning the K-16 continuum, the integrated program helps prepare and attract a student population whose diversity is representative of society at large (Carlson \& Sullivan, 2004). A growing emphasis of K-16 engineering program is the preparation and guidance of middle- and high-school students towards the university engineering and technology program. In light of the above discussion, this study intended to employ the notion of STEM to help students construct scientific understanding and real-world problem-solving skills by engaging them in a proposed engineering design process.

\section{STEM curriculum development}


The curriculum development in STEM requires teachers to set up an appropriate design task, in which two criteria are essential (Apedoe et al., 2008). Firstly, the task must be relevant to students' lives. Using a task that has personal relevance to students will increase student ownership and their excitement and interest in science and engineering design. Secondly, careful consideration must be given to the materials used in the design process, necessitating the use of tools for prototypes and working models. During the working process, the science materials need to be reliable and measured easily with these tools. Centered on an engineering design, there are two main types of STEM curriculum integration: content integration and context integration (Moore et al., 2014a; Moore et al., 2014b). Content integration focuses on the merging of content fields into a single curriculum in order to highlight over-arching learning goals, emerging from the subject content in each discipline and attributing to a related engineering design process. Context integration focuses on the content of one discipline and uses contexts from others to make the content more interesting, relevant, and challenging.

Content integration emphasizes on merging subject matter from multiple disciplines, and creates a curriculum that addresses content ideas from a combination of disciplines concurrently (Moore et al., 2014a). The curricular units explicitly contain learning objectives from individual STEM disciplines. For example, a socially relevant issue in improving quality of life, a STEM teacher might teach a unit that focuses on developing a coating to reduce frictional resistance of hip replacement joints to increase the lifespan of the product (Moore et al., 2014a). A stronger coating would increase the lifespan of hip replacements, reducing recipients' need for additional replacements. As another example, designing a method to clean up water in polluted ponds can incorporate a meaningful engineering design as part of the design method. This would introduce students to biological elements of clean water such as relationships within the ecosystem, and have students doing meaningful data analysis such as measuring $\mathrm{pH}$, nitrogen, and phosphorous levels over time (Moore et al., 2014c), which allows the integration of content from multiple disciplines, including mathematics, chemistry, physics, biology, and biomedical engineering.

On the other hand, context integration accents one discipline while using a second to frame the lesson content for the purpose of creating meaning and relevance (Moore et al., 2014a). That is, context integrations places the focus of one discipline above others and use the secondary disciplines to provide a setting or situation that creates meaning and relevance for learning the primary content (Moore et al., 2014c). In these situations, STEM content integration is meant to reveal connections between disciplines and make tasks more meaningful and interesting for the students, but the curricula does not seek to address any learning objectives from the secondary disciplines (Moore et al., 2014b). For example, the context could be a company that is examining the reliability of tires to increase the vehicle safety. The context is engineering, but the unit focus is statistics in math, specifically Chi-square testing. Another example is counting pelican colonies from aerial photos to save pelican nests from damage. The context is engineering design with environmental issues, but the content is mathematics: unit area, perimeter, density, and early ideas of ratio and proportional reasoning (Moore et al., 2014c).

No matter the method of content or context integration, combining content from multiple disciplines in a meaningful way is not an easy task. It is important to ensure that the essential aspects of each subject content areas are not lost through the process of integration (Glancy et al., 2014). Williams (2011) proposed that, rather than integration, a more reasonable approach may be to develop interaction between STEM subjects by fostering cross-curricular links and the integrity of each subject remains respected. Interaction, rather than integration, involves providing links between the subjects when the rationale for such is clear, and is related to teachers' judgments about expected learning outcomes for students (Williams, 2011). Meanwhile, teachers must be willing to collaborate with each other and to believe that interactions between subjects will provide enhanced learning opportunities for their students. The impetus for meaningful STEM links in schools must be grass roots driven, and requires partnerships between teachers with a shared vision (Barlex, 2007; Williams, 2011).

Finally, it is important to recognize the requirements of STEM curricula (Moore et al., 2014a): 
1. the context must be relevant and motivating so students develop personal connections to the learning,

2. students must engage in the design process that develops students' creativity and higher-order thinking skills,

3. students should have opportunities to learn from failure and redesign,the main objectives of the lesson must include meaningful and important mathematics and/or science content,

4. the lessons that incorporate non-STEM content, such as reading or social studies, are suggested,

5. the lessons must incorporate and emphasize teamwork and communication.

When the STEM curricula follow the above requirements, it is expected that the learning practices will (1) increase student interest in STEM disciplines, (2) deepen student understanding of each discipline by contextualizing concepts, (3) broaden student understanding of STEM disciplines through exposure to socially and culturally relevant contexts, and (4) encourage student to enter STEM fields (Moore et al., 2014a).

\section{Challenges in implementing engineering}

Contrary to many common education practices, engineering does not assign learning to stand-alone subject domains. Engineers use their understanding of subject-area knowledge and associated skills to understand the problems and make use of tools to test solutions (Katehi et al., 2009). One of the fundamental aspects of engineering is mathematics, which provides a means to represent relationships and properties, and to develop models for predicting outcomes. Mathematics, science, and technology provide the content knowledge of the world, in which problems need to be resolved through engineering design processes. Many of the concepts introduced in the classroom present engineering opportunities (Mann et al., 2011). For example, students learn about the properties of materials, the motion of objects, the phenomena of light, the transfer of heat, and the conduction of electricity. In the engineering design for electricity and magnetism (Mann et al., 2011), students are required to use their knowledge of electrical circuits to create an electrical and/or magnetic invention that serves a purpose (e.g., alarm circuit and electromagnet). In this case, the science concepts and technology knowledge include: Power, Voltage, Resistance, Insulators, Circuits, and Magnetism. The required mathematical concepts is Algebra: application of a variety of formulas for basic circuit design and measurement. These statements reveal the interwoven relationships among subject domains in STEM.

Oftentimes, engineering is viewed wrongly as a separate entity, and teachers hesitate to add more to their curriculum. Some teachers experience anxiousness because they are unfamiliar with engineering concepts and careers, feel uncomfortable with open-ended problems when using the design process, or express concern with problems that do not have one right answer (Katehi et al., 2009; Mann et al., 2011). Claims of not having time and minimal knowledge, in addition to a perception of being overworked, result in the conclusion that engineering cannot be added into the curriculum (Douglas, Iversen, \& Kalyandurg, 2004; Mann et al., 2011). It should also be clarified that integrating engineering into current teaching does not mean adding new curriculum. Engineering concepts could be demonstrated in all content areas but seldom are recognized as engineering.

It is therefore crucial to help teachers build up a descent understanding and attitude toward engineering design, which is not a new topic nor an un-precedent action to be added to students' existing over-loaded school work. People all naturally engage in design. People all use tools and materials purposefully when trying to suit their needs; thus, the capacity for design is a fundamental human aptitude (Fortus et al., 2004; Roberts, 1995). It is optimistic to expect that design-based activities have the potential to address a basic capability existent in all students (Fortus et al., 2004). Design is a particular, but representative, instance of real-world problem-solving, having no prescribed path leading from the required specifications to the final product design (Bucciarelli, 1994; Fortus et al., 2004). As the design product is the result of a wide range of value judgments, it is difficult to determine if a design product is the best solution to the requirements. 


\section{Engineering design process}

Engineering design requires the linkage of (1) narrative discussion/description, (2) graphical explanations, (3) analytical calculations, and (4) physical creation, and the connection of math, science and technology can be present in the design processes (Wicklein, 2006). Hence, engineering design might serve to form motivating contexts to integrate the other three STEM disciplines (Katehi, Pearson, \& Feder, 2009). The engineering design is meant to teach students that engineering is about organizing thoughts to form decision making for the purpose of developing better solutions and/or products for problems. The knowledge and skills associated with the process of engineering design do not depend on the engineering discipline (e.g., mechanical, electrical, civil, etc.) and/or engineering science (e.g., thermodynamics, statics, or mechanics) that a particular engineering problem is related to (Hynes et al., 2011). Design tasks entail developing critical thinking skills associated with engineering, technology, and science literacy.

The present study suggests using the technology tools of graphic-based programming for STEM in high schools. In general, graphical-based programming tools have a "low floor" (easy to get started) and a "high ceiling" (opportunities to create increasingly complex projects over time) (Lye \& Koh, 2014; Papert, 1980; Resnick et al., 2009). Resnick et al. (2009) proposed one additional requirement of "wide walls", supporting many different types of projects so students with many different interests and backgrounds can all become engaged. For example, App Inventor is the invention of MIT and is hosted at the MIT Center for Mobile Learning (Morelli et al., 2015). App Inventor is a blocks-based visual programming language enabling people with little to no previous programming experience to create mobile Apps for Android devices. It aims to transform the complex language of text-based coding into visual, drag-and-drop building blocks. The simple graphical interface grants novices the ability to design and deploy a basic, fully functional App. The Inventor tool offers various modules, which can be selected via "drag and drop", and added to a screen. Those modules support data collection, including making use of the built-in sensors of smartphones. The data accessed by sensors can later be displayed on the mobile screen for science learning. For example, smartphones contain a large number of built-in sensors, such as accelerometers, gyroscopes, magnetic sensors and light detectors, which allow students to perform multiple science measurements in non-classroom settings. Smartphone accelerometers are a simple and easy way for students to collect data for the analysis of free fall (Kuhn \& Vogt, 2013; Vogt \& Kuhn, 2012). From a simple measurement like this, the students can understand the decrease/increase of weight when the elevator starts/stops the descent. What is more, students can obtain some interesting and scientific conclusions after a numerical analysis of the accelerometer measurement data (González et al. 2014). A more complex physical system is the physical pendulum, which can be experimentally studied using the acceleration and rotation (gyroscope) sensors available on smartphones (Monteiro et al., 2014). On an amusement park pendulum ride, the resulting data in the measurements of the radial and tangential acceleration and the angular velocity obtained with smartphone sensors can be graphed to assist in the creation of force diagrams to help students explain their physical sensations while on the ride (Monteiro et al., 2014; Vieyra \& Vieyra, 2014). Students relate the graph of force diagrams to physical points on the ride and use Newton's laws of motion to explain and justify their physical sensations at those points on the ride. In this example, where the acceleration leads to forces experienced throughout the body, the connection between the experience of forces on and in the body and the mathematical description of motion helps students gain a deepened understanding of mechanics and its relevance outside the classroom (Pendrill \& Rohlen, 2011).

This study proposes giving students the opportunity to design mobile apps for their science learning. Students can prepare the software applications in the computer lab, defining the goal of the App, i.e., the data they need to collect and how to be collected for later applications. Once the application design is completed, it can be saved and later executed on a smartphone. Students are empowered with the capability to design and interact with the physical world through their own insight and programming determination. Xie et al. (2015) argued that the convergence of computing, connectivity, and content enables people to leverage their smartphones to solve problems they encounter in their daily life. For the students without much experience in computing programming or capabilities in operating sophisticated technology tools which are unaffordable 
for most high schools, the proposed graphic-based programming tools provide support and motivation for students participating in engineering design processes. For the specific case of App Inventor, it empowers all students to transition from being consumers of mobile learning applications to becoming creators through STEM engineering design processes.

Some suggestions about what students need to do and how teachers should help during the process of engineering design are adopted from Hynes et al. (2011). The further elaboration of the suggestions is given below. The suggestions should not be read as a rigid set of guidelines that must be followed, but rather as a set of guiding principles to consider in the teaching and learning of engineering. The engineering design process is a cyclical, stepwise process for solving real-world engineering problems. Oftentimes the task requires some jumping around from step to step.

\section{Identify and define problems}

When students are capable of identifying a need or problem in a given situation, they should be provided with the opportunity to do so. The problems should be ill-defined, and students need to acknowledge the design goals and identify the necessary constraints imposed on the problem. In addition, students might be given the opportunity to decompose a given situation in order to frame a problem in their own words (Koehler et al., 2005, Lemons et al., 2010). The problem needs to be open-ended with many possible solutions. This approach not only increases the likelihood of the students taking ownership of the problem, but it also provides students with an opportunity to practice critical thinking skills (Hynes et al., 2011). As the problem is ill-defined, students need to conduct some background research, and understand that there are many science and mathematics issues to consider when solving a real-world issue. Learning may begin with an exploration of students' interpretations and understandings of the science concepts to be addressed (Apedoe et al., 2008; Taber, 2003). Students will recognize that they need to fully explore the problem in order to be well-informed as to how to solve it. At this moment, teacher may scaffold the related curriculum which is necessary to the students. This approach allows students to comprehend that research is integral to the process of engineering design (Ennis \& Greszly, 1991). As students research the need or problem and discover new ideas or constraints, they will redefine and clarify the problem.

\section{Develop and select possible solution(s)}

The ultimate purpose of engineering design is to create a solution or an end product that solves the problem. Students need to be able to justify and rationalize the solution which they pursue. This requires that a better possible solution be selected for the project. What may seem the best for one person may not always seem best for another person. Recording possible solutions for the design task takes into consideration the need for planning and teamwork. Students should actively collaborate in groups to foster individual learning and creativity. Through this process, students practice their communication skills with others and understand tradeoffs while forming ideas within the problem criteria and constraints (Mullins, Atman, \& Shuman, 1999; Radcliffe \& Lee, 1989).

Students are advised that a perfect solution is rarely available to real-world problem. This requires students to back-up their ideas with proper evidences and issues that are discovered through research (Dym et al., 2005). This also assures that students use their knowledge of mathematics and science in their own words to make informed decisions, constantly assessing each choice along the way.

\section{Construct a prototype}

Building things is often the concept students have about engineering design prior to exposure to any engineering design (Hynes et al., 2011). This is clearly not the case, as the previous two activities describe the need for sufficient planning before engineering construction can begin. Iterative prototyping until an final product is reached is a key component of this stage (Hynes et al., 2011; Koehler et al., 2005). As students iterate on their solution, it is important to allow them to fail and learn from those failures. Regarding the construction 
a physical model, some students may have the conception of using 3D printer to make their final product, or solution to a problem. A 3D printer should be treated as prototype maker, not only an end-product maker. In addition, a prototype is a representation or model of the final solution, which can be physical, virtual, or mathematical (Hynes et al., 2011).

There may be a number of prototypes developed throughout the engineering design process that build upon each other or represent different characteristics of the final solution (Hynes et al., 2011). The prototype may not always perform like the intended final solution. Instead, it should illustrate some fundamental functionality or look of the proposed final solution.

\section{Test and evaluate the solution(s)}

Students must develop their own experimental tests based on the constraints and requirements of the problem to judge and evaluate their solutions and prototypes (Trevisan et al., 1998). Regarding the proposed graphic-based programming tools, students may tinker with quick feedback and interactive computational practices such as testing and debugging, which are cognitively less demanding. This allows students to acquire computational problem-solving practices more easily. Ultimately, these tools become "technology-as-partner in the learning process" (Jonassen, Howland, Marra, \& Crismond, 2008, p. 7) and can help students to extend these computational practices towards enhancing their general problem-solving skills.

The proposed graphic-programming tools can engage students in the building of digital products, thereby enabling programming activities to be used as a means to express their ideas. This can shape students' computational perspective about the computational tools and technological world. That is, computational perspectives entail students developing understandings of themselves and their relationships with others and the technological world (Lye \& Koh, 2014). It is cautioned that the programming experience may be non-educative as students are merely doing it in the trial-and-error mode without actively reflecting on their experience (Lye \& Koh, 2014). Hence, the students ought to be thinking-doing and not just doing (Lye \& Koh, 2014).

In this stage of engineering design, students are not expected to get the final solution in the first trial, and debugging is one of the required skills to find the solutions. Debugging encompasses four steps: 1) recognize that something is not meeting the goal, 2) either decide to continue to pursue the original plan or come up with an alternative, 3) generate a hypothesis as to the cause of the problem, and 4) attempt to solve the problem (Bers et al., 2014). In the engineering design process, the steps of evaluating and improving, which require debugging, are particularly important in establishing a learning environment where failure rather than immediate success is expected and seen as necessary for the design process (Bers et al., 2014). Debugging skills are not limited to the arena of computer science. With appropriate support and explicit instruction, students can transfer debugging skills to activities outside of the programming context (Bers et al., 2014; Klahr \& Carver, 1988).

As students have their final solution, they should present the design by detailing the specifications of their design and how it works scientifically (Apedoe et al., 2008). In this way, the presentation allows students to refine and connect their science and engineering knowledge. Meanwhile, to support the success of the above engineering design process and related learning activities, students should have the so-called Engineering habits of mind (Katehi, Pearson, \& Feder, 2009; Basham \& Marino, 2013). That is, in addition to acquiring knowledge and skills of engineering design, STEM education should also focus on the adoption of engineering habits of mind (Katehi, Pearson, \& Feder, 2009; Basham \& Marino, 2013), which include (1) systems thinking, (2) optimism and creativity, (3) collaboration and communication, and (4) attention to ethical considerations. Systems thinking requires students to recognize essential knowledge interconnections among the subject domains in STEM and their contributions to the value of engineering. Meanwhile, engineering systems may have effects that cannot be expected from the behavior of individual subsystems (Basham \& Marino, 2013). In every unexpected challenge engineering possibilities and opportunities can be found. Optimism and creativity thus are inherent in the engineering design process. Engineering is also about team work which requires engineers' collaboration; collaboration leverages the perspectives, knowledge, and skills of team members to tackle a de- 
sign challenge (Basham \& Marino, 2013). During team work, communication is essential to enable understanding of the requirements of an engineering problem, and to explain and justify the prototypes during the design process. Ethical considerations draw attention to the effects of engineering on society, including people and the environment.

\section{The proposed learning task of engineering design}

In science learning (for example Chemistry), complexity comes from its understanding of matter at three levels of representation: macroscopic, microscopic and symbolic (Gabel, 1999). Macroscopic refers to the observational experience in the laboratory and everyday life; microscopic level means the representation of the inferred nature of chemical entities (as atoms, ions, or molecules) and the relationships between them; symbolic level is the representation of the identities of entities (atoms, ions, or molecules) (Gilbert, 2005). It is difficult to develop an intuitive understanding of the connection between these three levels (Harrison \& Treagust, 2002). However, integrating the three levels of representation would provide a greater conceptual understanding of the subject content (Gabel, 1999). Incorporating hands-on practical work into the chemistry classroom is one way to help students strengthen their understanding of the connections between the macroscopic and the microscopic (Gabel, 1999). Therefore, the proposed learning task is intended to create a learning environment supporting students to integrate multiple types of representations with hands-on work.

The purpose of learning engineering design in STEM is to encourage students to experience engineering with hands-on activities as a practical application of math and science knowledge. The required hand-on activities and exercises of knowledge and skills are aligned with the Kolb's (1984) experiential learning cycle (Fig. 1). During the process of using computational tools for the creation or tinkering, as suggested in this study, students access and exercise their knowledge through practical work.

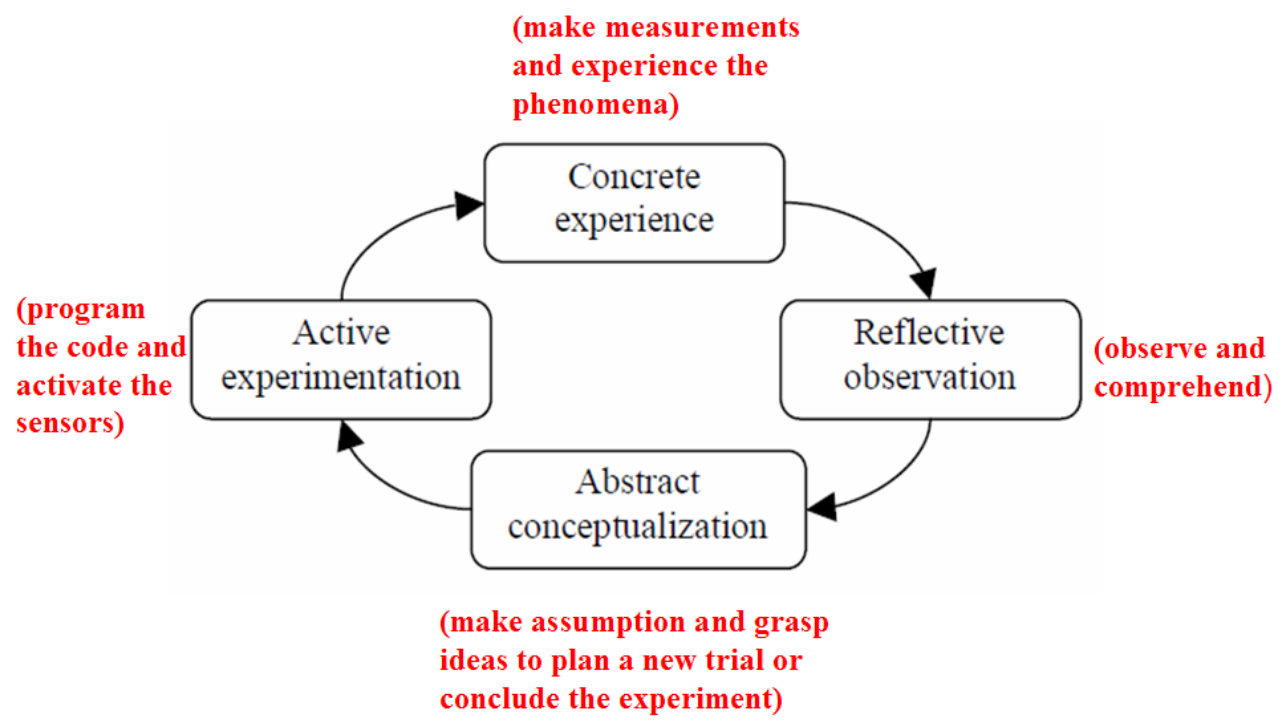

Figure 1. Modified Kolb’s (1984) experiential learning cycle

The experiential learning cycle is proposed to guide the development of micro-activities (creation or tinkering with computational artifacts) that integrate these phases and allow for a fluent transition among different types of learning activities in the engineering design process. Kolb argued that learning from experience is an appropriate way to acquire knowledge: "Learning is the process whereby knowledge is created through the transformation of experience" (Conradi et al., 2011; Kolb et al., 2000). His experiential learning cycle illustrates how learners construct and refine their knowledge through experimentation. After having a concrete experience, one can reflect on observations, conceptualize abstractly how it might work, and test these newly formed concepts through active experimentation. If the resulting experience and reflection do not fit the con- 
ceptualizations, they are adapted and tested with new experimentations (Conradi et al., 2011). The proposed task of engineering design is to tackle one general concern about hands-on activities, in which students do not learn the underlying science concepts through these activities, or the knowledge to be learned can be delivered through direct instruction (Apedoe et al., 2008; Kirschner et al. 2006).

In this study, the proposed use of graph-programming tools for STEM learning can support a quick tinkering process, when aligned with Kolb's experiential learning cycle, in which students program the code and activate the sensors (active experiment), make measurements and experience the phenomena (concrete experience), observe and comprehend (reflective observation), and make assumptions and grasp ideas to plan a new trial or conclude the experiment (abstract conceptualization)(Fig. 2). The digital test environment provides a tangible experience of physical theories and phenomena and supports reflection and conceptualization of digital information in situ. Students actively participate as programming engineers in engineering design processes. Students access and exercise knowledge and skills in the subject domains of science, mathematics, and technology to support their meaningful engineering design. Engineering design provides students with possibilities to use various science and math materials that they have been taught throughout their education. By incorporating engineering into the frameworks of traditional math and science, the paradigm shifts from rigid, content driven, and discipline-specific subject content to a more problem-based engineering design process. (Hynes et al., 2011; Koehler et al., 2005).

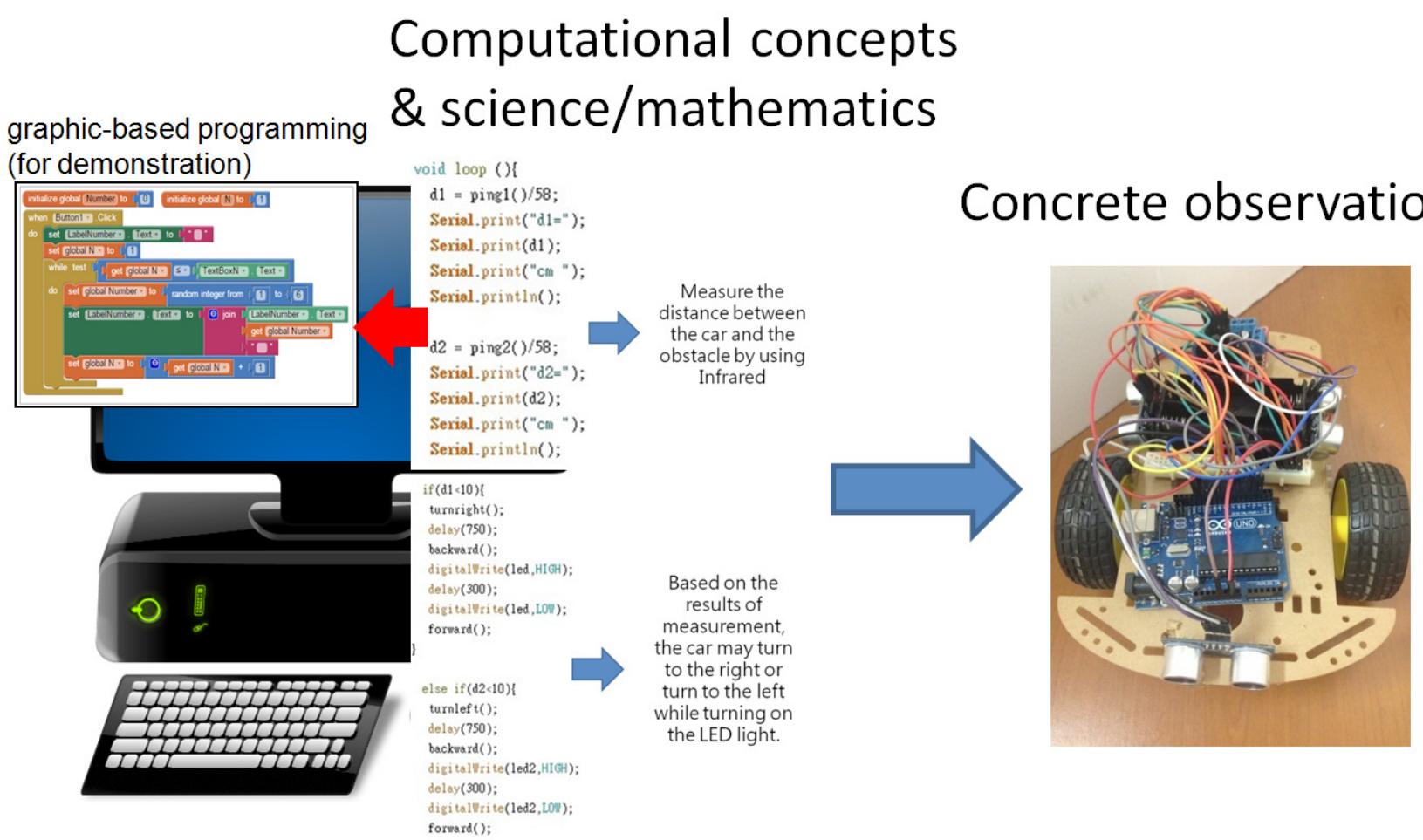

Figure 2. The proposed use of graph-programming tools for STEM learning

The proposed learning design and tools will help students acquire basic technicalities of programming which include computational concepts such as variables and loops. This study proposes that, in addition to the learning of computational concepts, students need to construct computational programs to access and manipulate the scientific data, and to implement the applications they design. Students learn to solve problems and acquire cognitive skills such as causal reasoning and metacognition. These are so-called computational practices, through which students can examine problem solving processes during programming. The proposed learning context may also entail students developing understandings of themselves and their relationships with the technology tools, smartphones, and the scientific world of physics, and hopefully transferring these competencies for general problem-solving. These are computational perspectives. The concepts, practices, and perspectives 
are three dimensions of computational thinking required for students (Lye \& Koh, 2014; Wing, 2008).

\section{Conclusions}

There is little consensus about what STEM is, and how it can be taught in schools. This study is intended to provide a snap shot of prominent contemporary research and propose some design concepts aiming to contribute to better understanding of STEM and the potential of its use in education. In this study, STEM is designed to help students acquire real-world problem-solving skills by engaging them in an engineering design process. The purpose of learning engineering design is to encourage students to experience engineering with hands-on activities as a practical application of math and science knowledge. The proposed instructional design including hand-on activities and exercises of knowledge and skills has been aligned with Kolb's (1984) experiential learning cycle. Moreover, the technology tools of graphic-based programming are used for STEM because graphical-based programming tools have the characteristics of low floor, high ceiling, and wide walls (Lye \& Koh, 2014; Papert, 1980; Resnick et al., 2009). Further proposed instruction design is the use of mobile app authoring tools, with which students can design the mobile apps in the computer lab, save the programs and later execute them on smartphones. Students are asserted to be empowered with the capability to design and interact with the physical world through their own insights and programming determinations. The convergence of computing, connectivity, and content enables students to leverage their smartphones to solve problems they encounter in their daily life (Xie et al., 2015). As the discussions of promising learning potential of the proposed designs await justifications, this study sheds new light on STEM and points to new possibilities for researchers and educators to adopt or tailor their own learning designs for the current digital-native generation.

\section{References}

Apedoe, X. S., Reynolds, B., Ellefson, M. R., \& Schunn, C. D. (2008). Bringing engineering design into high school science classrooms: The heating/cooling unit. Journal of Science Education and Technology, 17(5), 454-465.

Barlex, D. (2007). STEM: an important acronym. D\&T News (36). Warwickshire, UK: The Design and Technology Association.

Basham, J. D., \& Marino, M. T. (2013). Understanding STEM education and supporting students through universal design for learning. Teaching Exceptional Children, 45(4), 8-15.

Bers, M. U., Flannery, L., Kazakoff, E. R., \& Sullivan, A. (2014). Computational thinking and tinkering: Exploration of an early childhood robotics curriculum. Computers \& Education, 72, 145-157.

Blumenfeld, P. C., Soloway, E., Marx, R. W., Krajcik, J. S., Guzdial, M., \& Palincsar, A. (1991). Motivating project-based learning: Sustaining the doing, supporting the learning. Educational psychologist, 26(34), 369-398.

Bucciarelli, L.L. (1994). Designing engineers. Cambridge, MA: MIT Press.

Carlson, L. E., \& Sullivan, J. F. (2004). Exploiting design to inspire interest in engineering across the K-16 engineering curriculum. International Journal of Engineering Education, 20(3), 372-378.

Conradi, B., Lerch, V., Hommer, M., Kowalski, R., Vletsou, I., \& Hussmann, H. (2011). Flow of electrons: an augmented workspace for learning physical computing experientially. In Proceedings of the ACM International Conference on Interactive Tabletops and Surfaces (pp. 182-191). ACM.

Douglas, J., Iversen, E., \& Kalyandurg, C. (2004). Engineering in the K-12 classroom: An analysis of current practices and guidelines for the future. ASEE Engineering K12 Center. Retrieved from http://teachers. egfi-k12.org/wp-content/uploads/2010/01/Engineering_in_the_K-12_Classroom.pdf

Dym, C. L., Agogino, A. M., Eris, O., Frey, D. D. \& Leifer, L. J. (2005). Engineering design thinking, teaching, and learning. Journal of Engineering Education, 94(1), 104-120.

Ennis, C. W., \& Gyeszly, S. W. (1991). Protocol analysis of the engineering systems design approach. Research 
in Engineering Design, 3(1), 15-22.

Fortus, D., Dershimer, C., Krajcik, J., Marx, R., \& Mamlok-Naaman, R. (2004). Design-based science and student learning. Journal of Research in Science Teaching, 41(10), 1081-1110.

Gabel, D. (1999). Improving teaching and learning through chemical education research: a look to the future. Journal of Chemical Education, 76, 548-554.

Gilbert, J. K. (2005). Visualization: A metacognitive skill in science and science education. In Visualization in science education (pp. 9-27). Springer Netherlands.

Glancy, A. W., Moore, T. J., Guzey, S. S., Mathis, C. A., Tank, K. M., Siverling, E. A., (2014). Examination of integrated STEM curricula as a means toward quality K-12 engineering education (Research to Practice). age, 24, 1.

González, M. Á., González, M. Á., Llamas, C., Martín, M. E., Vegas, J., Martínez, Ó., ... \& Herguedas, M. (2014). Mobile phones for teaching physics: using applications and sensors. In Proceedings of the Second International Conference on Technological Ecosystems for Enhancing Multiculturality (pp. 349-355). ACM.

Harrison, A. G., \& Treagust, D. F. (2002). The particulate nature of matter: Challenges in understanding the submicroscopic world. In Chemical education: Towards research-based practice (pp. 189-212). Springer Netherlands.

Hirsch, L. S., Kimmel, H., Rockland, R., \& Bloom, J. (2005). Implementing pre-engineering curricula in high school science and mathematics. In Proceedings of the 35th Annual Conference Frontiers in Education, ed. H. Kimmel. Indianapolis, IN.

Hynes, M., Portsmore, M., Dare, E., Milto, E., Rogers, C., Hammer, D., \& Carberry, A. (2011). Infusing engineering design into high school STEM courses. National Center for Engineering and Technology Education.

Johnstone, A. H. (1991). Why is science difficult to learn? Things are seldom what they seem. Journal of computer assisted learning, 7(2), 75-83.

Jonassen, D., Howland, J., Marra, R.M., \& Crismond, D. (2008). Meaningful learning with technology (3rd ed.): Pearson/Merrill Prentice Hall.

Katehi L., Pearson, G., \& Feder, M. (Eds.) (2009). Engineering in K-12 education: Understanding the status and improving the prospects. Report from the Committee on K-12 Education for the National Academies. Washington DC: The National Academies Press.

Kirschner, P. A., Sweller, J., \& Clark, R. E. (2006). Why minimal guidance during instruction does not work: An analysis of the failure of constructivist, discovery, problem-based, experiential, and inquiry-based teaching. Educational psychologist, 41(2), 75-86.

Klahr, D., \& Carver, S. (1988). Cognitive objectives in a LOGO debugging curriculum: instruction, learning, and transfer. Cognitive Psychology, 20, 362-404.

Koehler, C., Faraclas, E., Sanchez, S., Latif, S. K., \& Kazerounian, K. (2005). Engineering frameworks for a high school setting: Guidelines for technical literacy for high school students. age, 10, 1.

Kolb, D. (1984). Experiential learning: Experience as the source of learning and development. Prentice-Hall.

Kolb., D., Boyatzis, R.E., \& Mainemelis, C. (2000). Experiential learning theory: Previous research and new directions. Perspectives on cognitive, learning, and thinking styles. Lawrence Erlbaum, 227-247.

Kuhn, J., \& Vogt, P. (2013). Smartphones as experimental tools: Different methods to determine the gravitational acceleration in classroom physics by using everyday devices. European J of Physics Education, 4(1).

Lemons, G., Carberry, A., Swan, C., Rogers, C., \& Jarvin, L. (2010). The importance of problem interpretation for engineering students. In American Society for Engineering Education. American Society for Engineering Education. 
Lye, S. Y., \& Koh, J. H. L. (2014). Review on teaching and learning of computational thinking through programming: What is next for K-12?. Computers in Human Behavior, 41, 51-61.

Mann, E. L., Mann, R. L., Strutz, M. L., Duncan, D., \& Yoon, S. Y. (2011). Integrating engineering into K-6 curriculum developing talent in the STEM disciplines. Journal of Advanced Academics, 22(4), 639-658.

Monteiro, M., Cabeza, C., \& Martí, A. C. (2014). Exploring phase space using smartphone acceleration and rotation sensors simultaneously. European Journal of Physics, 35(4), 045013.

Moore, T. J., Tank, K. M., Glancy, A. W., Siverling, E. A., \& Mathis, C. A. (2014a). Engineering to enhance STEM integration efforts, American Society for Engineering Education Annual Conference.

Moore, T. J., Stohlmann, M. S., Wang, H.-H., Tank, K. M., Glancy, A.W., \& Roehrig, G. H. (2014b). Implementation and integration of engineering in K-12 STEM education. In J. Strobel, S. Purzer, \& M. Cardella (Eds.), Engineering in precollege settings: Research into practice. Rotterdam, the Netherlands: Sense Publishers.

Moore, T. J., Mathis, C. A., Guzey, S. S., Glancy, A. W., \& Siverling, E. A. (2014c). STEM integration in the middle grades: A case study of teacher implementation. In Frontiers in Education Conference (FIE), 2014 IEEE(pp. 1-8). IEEE.

Morelli, R., Uche, C., Lake, P., \& Baldwin, L. (2015). Analyzing Year One of a CS Principles PD Project. In Proceedings of the 46th ACM Technical Symposium on Computer Science Education (pp. 368-373). ACM.

Mullins, C. A., Atman, C. J., \& Shuman, L. J. (1999). Freshman engineers' performance when solving design problems. IEEE Transactions on Education, 42(4), 281-287.

National Research Council (1996). National science education standards. Washington, DC: National Academy Press.

Papert, S. (1980). Mindstorms: Children, Computers, and Powerful Ideas. Basic Books, New York.

Pendrill, A.-M., \& Rohlen, J. (2011). Acceleration and rotation in a pendulum ride, measured using an iPhone 4. Physics Education, 46, 676-681.

Pitt, J. (2009). Blurring the Boundaries - STEM Education and Education for Sustainable Development. Design and Technology Education: An International Journal, 14(1), 37-48.

Radcliffe, D. F., \& Lee, T. Y. (1989). Design methods used by undergraduate engineering students. Design Studies, 10(4), 199-209.

Resnick, M., Maloney, J., Monroy-Hernández, A., Rusk, N., Eastmond, E., Brennan, K., ... Kafai, Y. (2009). Scratch: Programming for all. Communications of the ACM, 52, 60-67.

Roberts, P. (1995). The place of design in technology education. In D. Layton (Ed.), Innovations in science and technology education (pp. 27-38). UNESCO.

Trevisan, M. S., Davis, D. C., Crain, R. W., Clakins, D. E., \& Gentili, K. L. (1998). Developing and assessing statewide competencies for engineering design. Journal of Engineering Education, 87(2), 185-193.

Vieyra, R. E., \& Vieyra, C. (2014). Analyzing forces on amusement park rides with mobile devices. The Physics Teacher, 52(3), 149-151.

Vogt, P., \& Kuhn, J. (2012). Analyzing free fall with a smartphone acceleration sensor. The Physics Teacher, 50(3), 182-183.

Wicklein, R. C. (2006). Five good reasons for engineering as the focus for technology education. The Technology Teacher, 65(7), 25.

Williams, J. (2011). STEM education: Proceed with caution. Design and Technology Education: An International Journal, 16(1).

Wing, J. M. (2008). Computational thinking and thinking about computing. Philosophical Transactions of the 
Royal Society of London A: Mathematical, Physical and Engineering Sciences, 366(1881), 3717-3725.

Xie, B., Shabir, I., \& Abelson, H. (2015). Measuring the Usability and Capability of App Inventor to Create Mobile Applications. MIT Open access article, http://dspace.mit.edu/handle/1721.1/98913 